Federal Reserve Bank of Dallas

Globalization and Monetary Policy Institute

Working Paper No. 192

http://www.dallasfed.org/assets/documents/institute/wpapers/2014/0192.pdf

\title{
Trade Partner Diversification and Growth: How Trade Links Matter
}

\author{
Ali Sina Önder \\ University of Bayreuth \\ Hakan Yilmazkuday \\ Florida International University
}

September 2014

\begin{abstract}
We use network centrality measures to capture the trade partner diversification (TPD) of countries as revealed by their position in the international trade network. These measures are shown to enter long-run growth regressions positively and significantly, on top of trade openness and other control variables. Historical evidence based on threshold analyses shows that countries can use their trade networks to compensate for their low levels of financial depth, high levels of inflation, and low levels of human capital. This result is important especially for developing economies where, on average, financial depth is low, inflation is high, and human capital is low. Therefore, globalization of international trade is important as far as gaining access into better trade networks through multilateral free trade agreements is rather essential for developing countries.
\end{abstract}

JEL codes: F13, G20, O19

\footnotetext{
* Ali Sina Önder, University of Bayreuth, Department of Economics,(RW-1, VWL-E), Universitätsstrasse 30, D-95447 Bayreuth, Germany. 49-921-556085. ali-sina.oender@uni-bayreuth.de. Hakan Yilmazkuday, Florida International University, Dept. of Economics, 11200 SW 8th Street, Miami, FL 33199. 305-3482316. hyilmazk@fiu.edu. The views in this paper are those of the authors and do not necessarily reflect the views of the Federal Reserve Bank of Dallas or the Federal Reserve System.
} 


\section{Introduction}

Trade openness can support growth through providing access to large markets, lowcost intermediate inputs and higher technologies. Empirical analyses of Frankel and Romer (1999) and Wacziang and Welch (2008) provide evidence for a robust, statistically significant, and positive effect of international trade on growth. However, after controlling for the degree of trade openness, does it matter with which countries trade is achieved, i.e. is it important how a country is positioned within the international trade network? This is an important question from an uncertainty perspective that is highly considered in the international business cycle literature, because the structure of a country's connectivity to the rest of the world may help to hedge against the lack of development under alternative macroeconomic conditions.

We use centrality measures to define a country's position in the international trade network, which we refer to as Trade Partner Diversification (TPD) in this paper. Importance of the level of TPD possessed by a country is three-fold: first, TPD may be a substitute for financial development by hedging, diversifying and pooling risk arising from exchange rate risk (due to business uncertainties and disturbances in planning), because exchange rate risk is distributed among trading partners when countries have higher TPD. ${ }^{1}$ Accordingly, in the absence of financial development, for example, having an exchange rate crisis in one of the trading partners would have a fewer impact on growth when TPD is higher.

Second, TPD can compensate for high levels of inflation which often correspond to variable inflation as well. In particular, high inflation may create considerable uncertainty about future prices, interest rates, and exchange rates, which, in turn, increases the overall risk of business among potential trade partners due to the possibility of a devaluation and vulnerability to speculative attacks. ${ }^{2}$ However, having a higher degree of TPD would again distribute such risks among trading partners; e.g., the possibility of a bilateral depreciation (with respect to one currency) is much higher than the pos-

\footnotetext{
${ }^{1}$ Bailliu et al. (2003) have shown that exchange rate risk is reduced when exports are diversified across markets. See Levine (1997) for the connection between finance and trade. See Koren (2003) for the relation between hedging instruments and the cost of exchange rate uncertainty incurred by exporters.

${ }^{2}$ See Rousseau and Wachtel (2002) for a discussion on the channels through which inflation may negatively affect growth.
} 
sibility of a multilateral depreciation (with respect to a basket of currencies consisting of the currencies of the trade partners).

Third, TPD can compensate for increasing international shocks due to having higher degrees of trade openness. ${ }^{3}$ For example, as shown by Svaleryd and Vlachos (2002), increasing international fluctuations due to higher degrees of trade openness require better diversification of risk, which may well be achieved by TPD.

In the context of long-run growth, this paper investigates how TPD can be used for hedging, diversifying and pooling risk among trading partners. Using a cross-country panel data set between 1965 and 2004 for 83 countries, we first analyze whether TPD has any role in explaining long-run growth, given the degree of trade openness together with other control variables. Such an investigation requires a measure for TPD, for which, we consider three alternative definitions, all obtained by using bilateral trade data across countries. In order to consider the effects of trade policies (rather than the volume of trade), consistent with Wei (2000), we measure trade openness as "residual openness" that is obtained as the residuals of a regression in which exports plus imports over GDP are regressed on per capita income, country fixed effects, and time fixed effects.

The baseline regression analysis, which is robust to the endogeneity concerns, shows that TPD enters long-run growth equations positively and significantly, on top of the control variables including financial system (measured by financial depth), price stability (measured by inflation), human capital (measured by secondary education level), government size (measured by the government expenditure as a percentage of GDP), per capita income level and trade openness (measured by residual openness). Therefore, on average across all countries in the sample, there is a positive role of TPD on the long-run growth. This result is in favor of multilateral free trade agreements (MFTAs) rather than regional free trade agreements, where having MFTAs would improve the trade network of countries and thus increase their measures of TPD considered in this paper.

We also take into account the fact that countries having different macroeconomic conditions may get affected asymmetrically by their measures of TPD regarding their

\footnotetext{
${ }^{3}$ See Rodrik (1998) who has emphasized the role of international fluctuations (imported through trade openness) in growth.
} 
long-run growth. Accordingly, we continue with a threshold investigation for which we consider alternative sets of countries distinguished with respect to their financial system (measured by financial depth), price stability (measured by inflation), human capital (measured by secondary education level), government size (measured by the government expenditure as a percentage of GDP), per capita income level and trade openness (measured by residual openness). The results show that TPD positively and significantly contributes to the long-run growth of countries which lack a developed financial system, price stability or advanced human capital, after controlling for the degree of trade openness. Moreover, TPD positively and significantly contributes to the long-run growth of countries with any level of government size, per capita income level, or trade openness. Therefore, in the context of long-run growth, TPD can hedge for the lack of development due to financial development, inflation and human capital. This result is important especially for developing economies where, on average, financial depth is low, inflation is high, and human capital is low; therefore, such developing countries could grow faster by gaining access into new markets and improving their trade networks through free trade agreements. TPD also captures indirect effects that a country's trade partners have on this country. As a result, globalization of international trade through multilateral free trade agreements rather than bilateral free trade agreements turns out to be important for developing countries.

While this paper is focusing on the relationship between economic growth and the diversification of trade partners, the existing literature has mostly focused on the relationship between economic growth and the diversification of goods exported. Kali et al. (2013) provide a powerful analysis using network density and proximity measures linking all internationally traded products and products traded by a country, and they unravel characteristics of the growth acceleration process, which supports the findings of Cadot et al. (2011) who show that a country travels along diversification cones as its income grows. ${ }^{4}$ Therefore, the analysis in this paper captures the effects of country-specific shocks on growth, while the analyses in the existing literature capture the effects of industry/good-specific shocks on growth. However, as shown by Costello (1993) and Karadimitropoulou and Len-Ledesma (2013) from a business cycle perspective through variance decomposition analyses, fluctuations are dominated

\footnotetext{
${ }^{4}$ See Cadot et al. (2013) for an excellent survey on diversification of export goods and growth.
} 
by country-specific shocks rather than industry/good-specific shocks. Hence, the existing literature has missed an important transmission mechanism of global shocks to country-specific growth rates; this paper bridges this gap by focusing on trade partner diversification.

The rest of the paper is organized as follows. The next section introduces measures of TPD. Section 3 introduces the trade data set and achieves descriptive statistics based on TPD. Section 4 introduces the growth data set and employs long-run growth regressions, and the last section concludes.

\section{Measuring Trade Partner Diversification (TPD)}

In this section we explain how the TPD is obtained, we discuss its various aspects and provide interpretations with help of a simple example. The collection of bilateral trade links between countries yields the basic structure of the international trade. Connections between pairs of countries in the international trade network at time $t$ are captured by the adjacency matrix $\mathbf{A}(\mathbf{t})$ where

$$
A(t)_{i j}=\left\{\begin{array}{l}
1, \text { if there is export of goods from country } i \text { to country } j \\
0, \text { if there is no export of goods from country } i \text { to country } j
\end{array}\right.
$$

Since the direction of export flows is important, $\mathbf{A}$ need not be symmetric, i.e. $a_{i j}=1$ does not necessarily imply $a_{j i}=1$.

A country's TPD is captured by network centrality measures assessing its position in the international trade network. For this end we employ three centrality measures, namely export degree, export closeness, and eigenvector centrality.

Suppose there are $n$ countries at time $t$ in the international trade network. Fraction of country $i$ 's existing export links to the total number of countries (excluding itself) is the export degree of country $i$, and we denote it by $E D(t)_{i}$ such that:

$$
E D(t)_{i}=\frac{1}{n-1} \sum_{j} a(t)_{i j}
$$

Export degree takes on values from zero to one: $E D(t)_{i}=1$, if country $i$ is exporting to every possible country in the international trade network at time $t$, and $E D(t)_{i}=0$, if country $i$ does not export anywhere. 
Distance between any two countries $i$ and $j$ in the international trade network is the geodesic distance measured by the length of the shortest path connecting the two countries: if country $i$ is exporting to country $j$, then the distance from $i$ to $j$ is one. If country $i$ does not export to country $h$, but it exports to country $j$, and country $j$ exports to country $h$, then the distance from country $i$ to country $h$ is two. If countries $i$ and $j$ are not connected by any collection of edges, then the distance is assumed to be infinite, but it remains a practical issue as to how big "infinity" should be. For our empirical analysis we take the infinite distance to be equvalent of a geodesic of 10. It is important to note that distances may change over time as new export links get established. All such bilateral distances in the international trade network at time $t$ are collected in the distance matrix $\mathbf{D}(\mathbf{t})$ where an element $D(t)_{i} j$ is the distance from country $i$ to country $j$ following export links in the international trade network. Export closeness of country $i$ at time $t$ is calculated by

$$
E C(t)_{i}=\frac{n-1}{\sum_{j} D(t)_{i j}}
$$

and it takes on values from zero to one, increasing as a country gets closer to the rest of the world. Export closeness adds valuable information on top of what we already know from the export degree of a country: not only do we care whether there is direct trade between country $i$ and the rest of the world, we also care for the network distance from country $i$ to countries that are no direct trade partners of it.

Thus the export closeness of country $i$ captures existing as well as potential export drive of country $i$ and takes into account how well country $i$ 's trading partners perform in the export market. Suppose two countries $i$ and $j$ are only exporting to countries $k$ and $l$, respectively, but $k$ exports to all countries and $l$ does not export anywhere. Hence country $i$ has a distance of 1 from one country and 2 from all other countries, whereas country $j$ has a distance of 1 from one country and infinity from all other countries. Although both countries score the same in terms of export degree, $E D(t)_{i}=$ $E D(t)_{j}=1$, they don't have the same score for export closeness: $E C(t)_{j}$ turns out to be very close to zero and $E C(t)_{i}>E C(t)_{j}$. Thus export closeness gives a country credit for having access to the export market of a country that itself has access to other export markets which the former country does not have.

The third measure we employ in our analysis is the eigenvector centrality of coun- 
tries in the international trade network, as proposed by Bonacich (1987). Eigenvector centrality captures the idea that centrality of a country must be proportional to the centrality of countries where it exports to. This is also refered to as the prestige or influence (Newman, 2010). Technically, the eigenvector centrality is inversely related to the leading eigenvector of the adjacency matrix of the international trade network.

According to this measure, not only the total number of direct links is important due to this measure, but also the prestige of those links is important: for high eigenvector centrality, a country should be connected to countries that are also well connected and thus have prestige.

Next we provide a simple example for the international trade network where we apply these four network measures and discuss what they capture. We further show how these measures evolve as new trade links are established. Suppose the world consists of eight countries, and exports flow between these countries as depicted in figure 1.

Direction of an arrow from one country to another shows the direction of export flow between these countries: e.g. country 1 is exporting to countries 3 and 4 , but country 1 imports only from country 4 . There are two blocks that are not interconnected: countries 1 to 5 make up one block, and countries 6, 7, and 8 make up the other one. Distance between these two blocks is thus infinite ${ }^{5}$. We calculate our Trade Partner Diversification (TPD) measures for these eight countries and present the results in Table 1.

Export degree captures overall export market access of a country: country 4 exports to $43 \%$ of all countries, while country 8 is not exporting anywhere. Countries 1, 5, and 7 have the same export degree, but according to the export closeness, country 7 is further away from the rest of the world than countries 1 and 5. This follows from the positioning of country 7: it exports to countries which are not connected to any other country besides country 7 .

Eigenvector centrality is increasing in a country's export degree and the connectivity of countries that import from that country. Countries 2 and 3 have identical export degree and very close export closeness. When it comes to the eigenvector centrality, country 2 has a better measure, which reveals that countries that import from country

\footnotetext{
${ }^{5}$ We assume the infinite distance to be 10 when we calculate the export closeness measure.
} 
2 are themselves exporting to either a lot of countries or key exporters. Although countries 1 and 5 have the same export degree and closeness, country 5 is a more important player in the international trade network than country 1 according to the eigenvector centrality measure. Countries 6,7 , and 8 have zero eigenvector centrality, because they are not connected to any important exporter.

Next we illustrate how new export links change our TPD measures. Suppose that country 2 starts exporting to country 8 , and after a while country 8 starts exporting to country 2. These new export links are depicted in figure 2 in panels (a) and (b), respectively.

Table 2 lists our revised TPD measures for each country based on their position in the international trade network. Each measure has two columns (a) and (b), corresponding to networks depicted in figure 2's panels (a) and (b), respectively. When country 2 starts exporting to country 8 , this directly affects the export degree of country 2. Moreover, closeness of most countries is being affected positively. It is worth mentioning that the new export link does not affect the eigenvector measure of any country. This is simply because the exporter, country 2 in this case, is not getting any prestige from exporting to country 8 , because country 8 itself has no prestige.

When country 8 starts exporting to country 2 , this leads to several curious changes in eigenvector centralities: country 2's import demand generates prestige for country 8. Since country 8 now has prestige, i.e. non-zero eigenvector centrality, this also leads to non-zero eigenvector centralities for countries 6 and 7 . Thus as new export links are being established over time, eigenvector centrality is very sensitive to the case that a low prestige country starts exporting, especially to a prestigious country.

\section{Trade Data and International Trade Networks}

Our trade dataset contains bilateral trade flows between 83 countries from 1965 to 2004; this is a subset of the trade data set of Rose and Spiegel (2011) that covers the annual real FOB exports. ${ }^{6}$ The list of countries is given in the note under Table 1. In this section, we describe how the TPD measures evolve over time for a selected group of countries. It is not the aim of this paper to provide a full discussion of the international

\footnotetext{
${ }^{6}$ We focus on this subset to be consistent with our growth data set, below.
} 
trade network ${ }^{7}$. Our aim is to provide insight for how the TPD measures evolve over time for different countries, because patterns of these measures are important for the subsequent econometric analysis and interpretation of our results in the next section.

In this section, we briefly describe the positions of the United States, Brazil, and Israel in the world trade network. Being a rich and large country, US has been one of the most important players in the world trade. Brazil and Israel are developing countries that differ by the characteristics of their trade goods: Brazil has long been an exporter of raw materials and agricultural products whereas Israeli exports rely on capital intensive manufactures. A common pattern for export degree and export closeness is that both display an increasing trend over time for most countries in our dataset. Eigenvector centrality reveals an interesting pattern: as discussed in the previous section, already well-connected countries lose network prestige measured in eigenvector centrality, as the rest of the trade network establishes further links to outsiders. This trend is obvious for the US. Since Brazil and Israel rose rather later in the world trade, their trade network centrality measures reveal different patterns.

The United States is one of the most important players in the international trade. The US was exporting to about $75 \%$ of the countries that show up in our data in 1965 , and to more than $95 \%$ of countries in 2004. Connecting to different trade partners and hence establishing more links necessarily cuts down the overall distance of the US to other countries which leads to a higher centrality measure over years. The decrease in the eigenvector centrality of the US in 1980s captures the fact that the world trade network kept growing in this decade, and export markets of the US lost their relative importance which in return led to US losing its importance in the world trade network as measured by the eigenvector centrality.

Trade network measures for Brazil reveal an even more interesting story: Brazil's export markets made up $40 \%$ of countries that were actively trading in 1965, and in 2004 Brazil's exports reached about $90 \%$ of countries. Although the trend of the degree centrality measure is increasing and thus similar to that of the US in that respect, its relative change from $40 \%$ to more than $90 \%$ is impressing. The increase in

\footnotetext{
${ }^{7}$ See De Benedictis and Tajoli (2011) for a recent and detailed description of the international trade network with implications on trade structure. Also see Serrano and Boguña (2003) for the analysis of complex network properties observed in the international trade network.
} 
Brazil's eigenvector centrality during 1960s and 70s show that Brazil gained access to prestigious markets in these years.

Export market access of Israeli goods has experieced a downward trend from 1970 until late 1980s, as revealed by the degree centrality. During the same period, eigenvector centrality for Israel has been decreasing as well. The decrease in the eigenvector centrality turned out to be strong, because the downward trend is fed by two factors at the same time: first, world trade network is getting more dense over time and this creates a downward pressure on a country's eigenvector centrality even if a country keeps its share of access to world's export markets from previous periods. Second, even if the world trade network remained stable except for one country that loses its existing export links, this country is bound to lose its prestige as captured by the eigenvector centrality. In the Israeli case, the world trade network grows more dense (most countries establish new export links and their degree increases) and Israel loses in degree centrality, thus the two forces mentioned above work in the same direction and lead to an even stronger decrease in its eigenvector centrality.

\section{Growth Data and Baseline Growth Regressions}

The data set has been constructed for 83 countries covering the period 1965-2004 as a panel of country observations from the World Banks World Development Indicators and International Monetary Fund's Direction of Trade CD-ROM. The list of countries is the same as the one that we have for the trade data, which can be found in the note under Table 3.

Following Barro (1991) and Levine and Renelt (1992), the baseline growth equations includes a standard set of explanatory variables that provide robust and widely accepted proxies for growth determinants. The dependent variable is the growth rate of real per capita output averaged over 5-year periods from 1965 to 2004. On top of TPD measures that are new in this paper, the baseline regression analysis includes standard explanatory variables, such as log initial per capita GDP, log initial secondary enrollment rate (SEC), the ratio of liquid liabilities (i.e., M3) to GDP, inflation rate, trade openness, and government size. In order to consider the effects of trade policies (rather than the volume of trade), consistent with Wei (2000), we measure trade openness as 
"residual openness" that is obtained as the residuals of a regression in which exports plus imports over GDP are regressed on per capita income, country fixed effects, and time fixed effects. ${ }^{8}$ Estimation is achieved by Two-Stage Least Squares (TSLS) with initial values of the corresponding variables used as instruments in the first stage for each 5-year period. Time fixed effects for 5-year periods have been included to control for shocks with common growth effects across the countries. For robustness, country fixed effects are also considered in order to capture any country-specific characteristics that are constant over time, such as their geographical location or historical experience/institutions.

The corresponding descriptive statistics are given in Table 3. As is evident, TPD measures are positively correlated with per capita income growth and with each other; however, they are not correlated (either negatively or positively) with trade openness. In other words, TPD measures are expected to have significant effects on long-run growth on top of the trade openness measure which is also positively correlated with per capita income growth. For sure, these are just descriptive statistics; we need something formal in order to show the effects of TPD measures econometrically.

Accordingly, the regression results are given in Table 4 where we have excluded country fixed effects as the benchmark case. As is evident, all TPD measures are positive and significant at $1 \%$ level, with or without trade openness measure included in the regressions. All other control variables have their expected signs, although inflation is the only variable that is insignificant at any considered level. When country fixed effects are also included for robustness, the results in Table 4 are replaced with the results in Table 5, where, again, all TPD measures are positive and significant at $1 \%$ level, although some of the control variables have changed their estimated signs and/or significance. Therefore, robust to the inclusion of country fixed effects, trade openness and other control variables, TPD measures are significant and positive in all considered cases.

It is important to recall that a country's export degree changes only via direct export links, whereas a country's export closeness and eigenvector centrality change either via direct export links or when countries importing from this initial country establish new

\footnotetext{
${ }^{8}$ We also considered the raw trade openness measure of exports plus imports over GDP; the results were virtually the same.
} 
export links. Hence an important policy implication follows: multilateral rather than bilateral (or regional) free trade agreements should be preferred for higher long-run growth rates, because two out of three measures of TPD that is considered in this paper would be affected positively for a country when new export links are established by its export partners, even if this country itself does not establish new export links. Export closeness and eigenvector centrality increase even further when a country and its current partners establish new links at the same time. This benefit structure further implies that multilateral trade negotiations may be able to reach more efficient outcomes compared to bilateral negotiations due to positive externalities of new export links as they are captured by export closeness and eigenvector centrality.

Since countries having alternative macroeconomic conditions may get affected differently, we also consider thresholds in our right hand side variables in the growth regressions. Following Yilmazkuday (2011), rolling-window two-stage least squares regressions are employed with a constant window size of 200 after ordering the data according to the threshold variable. For instance, if the inflation thresholds were of interest, all the observations (i.e., the pooled sample of 5-year average data from all the countries) are sorted in the order of the lowest to the highest inflation rates; the first regression was run with the first 200 observations of the sorted data set, the second regression by moving the 200 window toward higher inflation rates by one observation, and so on. The selection of a constant window size was important for comparison of coefficient estimates across the windows, while the selection of a window size of 200 was important to ensure a fair distribution across the power of the regressions and the degree of nonlinearity. For a consistent inference across linear and nonlinear frameworks, the rolling-window regressions use the specifications in Columns 4-6 of Table 5.

The rolling-window regression results are given in Figures 6 to 11, where the x-axes show the median of the threshold variable in 200 sample windows (i.e., the variable according to which all the observations have been sorted). The y-axes of the figures in the left panel of the figures show the coefficient estimates of TPD measures. The bold solid lines show the coefficient estimates and the dashed lines the 10-percent confidence intervals. As is evident in Figures 6 to 8 , the positive effects of TPD on growth are more evident when financial development is lower, inflation is higher, 
human capital is lower, and trade openness is higher. Nevertheless, in Figures 9 to 11, such effects are relatively stable across alternative levels of trade openness, government size and log-initial GDP. Therefore, countries can use their trade networks (measured by TPDs in this paper) to compensate for their low levels of financial depth, high levels of inflation, and low levels of human capital. This result is important especially for developing economies where financial depth is low, inflation is high, and human capital is low; for instance, such countries could grow faster by getting involved into better trade networks through multilateral (rather than regional) free trade agreements.

\section{Conclusion}

International business cycles are shown to be dominated by country-specific shocks. Therefore, the trade network with which international trade is achieved (i.e., the variety of countries measured by Trade Partner Diversification, TPD) is important from the perspective of uncertainty. This paper shows that TPD enters long-run per capita growth regressions positively and significantly on top of trade openness and other standard control variables in the literature. Hence, from a welfare perspective, controlling for all else, having international trade with a wider set of countries is important for faster growth/development.

Using threshold analyses, it is also shown that countries can use their trade networks to compensate for their low levels of financial depth, high levels of inflation, and low levels of human capital. This result is important especially for developing economies where, on average, financial depth is low, inflation is high, and human capital is low. Therefore, getting involved into better and wider trade networks through multilateral (rather than bilateral or regional) free trade agreements, hence globalization of international trade, is more important, especially for developing countries.

\section{References}

Bailliu, J., Lafrance, R. and Perrault, J.F. 2003. "Does Exchange Rate Policy Matter for Growth?" International Finance. 6(3): p.381-414.

BARro, R.J. 1991. "Economic Growth in a Cross Section of Countries." Quarterly 
Journal of Economics. 106: 407443.

Bonacich, P. 1987. "Power and Centrality: a Family of Measures." American Journal of Sociology. 92(5): 1170-1182.

Cadot, O., Carrre, C. And Strauss-Kahn, V. 2011. "Export Diversification: What's Behing the Hump?" The Review of Economics and Statistics. 93(2): 590605.

Cadot, O., Carrre, C. and Strauss-Kahn, V. 2013. "Trade diversification, income, and growth: What do we know?" Journal of Economic Surveys. 27(4): 790812.

Costello, D. 1993. "A Cross-country, Cross Industry Comparison of Productivity Growth." Journal of Political Economy. 101: 206222

De Benedictis, L., And Tajoli, L. 2011. "The World Trade Network." The World Economy. doi:10.1111/j.1467-9701.2011.01360.x.

Frankel, J.A., And Romer, D. 1999. "Does Trade Cause Growth?" American Economic Review. 89(3):379-399.

Kali, R., Reyes, J., McGee, J., And Shirrell, S. 2013. "Growth Networks." Journal of Development Economics. 101:216-227.

Karadimitropoulou, A, and Len-Ledesma, M. 2013. "World, Country, and Sector Factors in International Business Cycles." Journal of Economic Dynamics and Control. 37(12): 2913-2927

Klingeroren, M. 2003. "Financial Globalization, Portfolio Diversification, and the Pattern of International Trade." IMF Working Paper. 03/233.

Koren, M. 2003. "Financial Globalization, Portfolio Diversification, and the Pattern of International Trade." IMF Working Paper. no.03/233.

Levine, R. 1997. "Financial Development and Economic Growth: Views and Agenda." Journal of Economic Literature. 35: 68872

Levine, R. And Renelt, D. 1992. "A Sensitivity Analysis of Cross-country Growth Regressions." American Economic Review. 82: 942963.

Newman, M.E.J. 2010. Networks: An Introduction. Oxford University Press.

RoDRIK, D. 1998. "Why Do More Open Economies Have Bigger Governments?" Journal of Political Economy. 106(5): 997-1032.

Rose, A. And Spiegel, M. 2011. "The Olympic Effect." The Economic Journal. 121(553): 652-677.

Rousseau, P.L. And Wachtel, P. 2002. "Inflation Thresholds and the Finance- 
Growth Nexus." Journal of International Money and Finance. 21: 777793.

Serrano, M.A., And Boguña, M. 2003. "Topology of the World Trade Web." Physical Review E. 68, 015101.

Svaleryd, H. And Vlachos, J. 2002. "Markets for Risk and Openness to Trade: How Are They Related?" Journal of International Economics. 57: 369-395.

Wacziang, R., And Welch, K.H. 2008. "Trade Liberalization and Growth: New Evidence." The World Bank Economic Review. 22(2):187-231.

WeI, S.J. 2000. "Natural Openness and Good Government." NBER Working Paper. no.7765

YilmaZkUdAY, H. 2011. "Thresholds in the Finance-Growth Nexus: A Cross-country Analysis." The World Bank Economic Review. 25(2):278-295. 
Table 1: Network centralities as TPD measures

Eigenvector

Country Export Degree Export Closeness Centrality

\begin{tabular}{lccc}
\hline 1 & 0.29 & 0.194 & 0.45 \\
2 & 0.14 & 0.179 & 0.29 \\
3 & 0.14 & 0.175 & 0.16 \\
4 & 0.43 & 0.2 & 0.64 \\
5 & 0.29 & 0.194 & 0.52 \\
6 & 0.14 & 0.132 & 0 \\
7 & 0.29 & 0.135 & 0 \\
8 & 0 & 0.1 & 0 \\
\hline \hline
\end{tabular}

Table 2: Revised TPD measures

Eigenvector

Country Export Degree Export Closeness Centrality

\begin{tabular}{ccccccc} 
& $(\mathrm{a})$ & $(\mathrm{b})$ & $(\mathrm{a})$ & $(\mathrm{b})$ & $(\mathrm{a})$ & $(\mathrm{b})$ \\
\hline 1 & 0.29 & 0.29 & 0.24 & 0.24 & 0.45 & 0.41 \\
2 & 0.29 & 0.29 & 0.23 & 0.23 & 0.29 & 0.37 \\
3 & 0.14 & 0.14 & 0.218 & 0.219 & 0.16 & 0.19 \\
4 & 0.43 & 0.43 & 0.25 & 0.25 & 0.64 & 0.58 \\
5 & 0.29 & 0.29 & 0.25 & 0.25 & 0.52 & 0.5 \\
6 & 0.14 & 0.14 & 0.132 & 0.26 & 0 & 0.07 \\
7 & 0.29 & 0.29 & 0.134 & 0.33 & 0 & 0.14 \\
8 & 0 & 0.14 & 0.1 & 0.21 & 0 & 0.19 \\
\hline \hline
\end{tabular}


Table 3: Descriptive Statistics, 1965-2004, 83 Countries

\begin{tabular}{|c|c|c|c|c|c|}
\hline Variable & $\begin{array}{l}\text { Per capita } \\
\text { income } \\
\text { growth (\%) }\end{array}$ & $\begin{array}{c}\text { Trade } \\
\text { (\% of GDP) }\end{array}$ & $\begin{array}{l}\text { Export } \\
\text { Degree }\end{array}$ & $\begin{array}{c}\text { Export } \\
\text { Closeness }\end{array}$ & $\begin{array}{c}\text { Eigenvector } \\
\text { Centrality }\end{array}$ \\
\hline Mean & 1.78 & 53.68 & 48.85 & 65.84 & 8.56 \\
\hline Maximum & 11.66 & 113.20 & 97.81 & 97.85 & 16.70 \\
\hline Minimum & -9.27 & 8.92 & 0.00 & 10.00 & 0.00 \\
\hline Standard deviation & 2.68 & 10.43 & 25.78 & 14.09 & 3.49 \\
\hline Coefficient of Variation & 1.51 & 0.19 & 0.53 & 0.21 & 0.41 \\
\hline \multicolumn{6}{|l|}{ Correlations } \\
\hline $\begin{array}{c}\text { Per capita } \\
\text { income growth (\%) }\end{array}$ & 1.00 & & & & \\
\hline Trade (\% of GDP) & 0.16 & 1.00 & & & \\
\hline Export Degree & 0.25 & 0.03 & 1.00 & & \\
\hline Export Closeness & 0.21 & 0.04 & 0.95 & 1.00 & \\
\hline Eigenvector Centrality & 0.34 & 0.00 & 0.88 & 0.80 & 1.00 \\
\hline
\end{tabular}

Source: Authors' analysis based on data sources discussed in the text.

Notes: The list of 83 countries is as follows: Algeria, Argentina, Australia, Austria, Bangladesh, Barbados, Belgium, Bolivia, Brazil, Cameroon, Canada, Central African Republic, Chile, Colombia, Costa Rica, Cote d'Ivoire, Denmark, Dominican Republic, Ecuador, Egypt, El Salvador, Fiji, Finland, France, Gambia, Ghana, Greece, Guatemala, Guyana, Haiti, Honduras, Iceland, India, Indonesia, Iran, Ireland, Israel, Italy, Jamaica, Japan, Jordan, Kenya, Korea Rep., Luxembourg, Malawi, Malaysia, Malta, Mauritius, Mexico, Morocco, Nepal, Netherlands, New Zealand, Nicaragua, Niger, Nigeria, Norway, Pakistan, Panama, Papua New Guinea, Paraguay, Peru, Philippines, Portugal, Rwanda, Senegal, Sierra Leone, South Africa, Spain, Sri Lanka, Sudan, Sweden, Switzerland, Syria, Thailand, Togo, Trinidad and Tobago, Turkey, United Kingdom, United States, Uruguay, Venezuela, Zimbabwe. 
Table 4: Instrumental variables growth regressions, 1965-2004, 83 Countries

\begin{tabular}{|c|c|c|c|c|c|c|}
\hline \multirow[b]{2}{*}{ Variables } & \multicolumn{6}{|c|}{ Dependent Variable: Growth of Per Capita Income (\%) } \\
\hline & (1) & $(2)$ & (3) & (4) & (5) & (6) \\
\hline Export Degree & $\begin{array}{c}0.022^{* *} \\
(0.006) \\
{[3.409]}\end{array}$ & & & $\begin{array}{c}0.020^{* *} \\
(0.006) \\
{[3.268]}\end{array}$ & & \\
\hline Export Closeness & & $\begin{array}{c}0.040^{* *} \\
(0.011) \\
{[3.520]}\end{array}$ & & & $\begin{array}{c}0.037^{* *} \\
(0.011) \\
{[3.304]}\end{array}$ & \\
\hline Eigenvector Centrality & & & $\begin{array}{c}0.161^{* *} \\
(0.046) \\
{[3.525]}\end{array}$ & & & $\begin{array}{c}0.159 * * \\
(0.045) \\
{[3.546]}\end{array}$ \\
\hline Trade (\% of GDP) & & & & $\begin{array}{c}0.033^{* *} \\
(0.012) \\
{[2.791]}\end{array}$ & $\begin{array}{c}0.032^{* *} \\
(0.012) \\
{[2.764]}\end{array}$ & $\begin{array}{c}0.034^{* *} \\
(0.012) \\
{[2.945]}\end{array}$ \\
\hline M3 (\% GDP) & $\begin{array}{c}0.018^{* *} \\
(0.005) \\
{[3.535]}\end{array}$ & $\begin{array}{c}0.018^{* *} \\
(0.005) \\
{[3.621]}\end{array}$ & $\begin{array}{c}0.019 * * \\
(0.005) \\
{[3.667]}\end{array}$ & $\begin{array}{c}0.017^{* *} \\
(0.005) \\
{[3.364]}\end{array}$ & $\begin{array}{c}0.017^{* *} \\
(0.005) \\
{[3.462]}\end{array}$ & $\begin{array}{c}0.017^{* *} \\
(0.005) \\
{[3.448]}\end{array}$ \\
\hline Inflation (\%) & $\begin{array}{l}-0.008 \\
(0.011) \\
{[0.752]}\end{array}$ & $\begin{array}{c}-0.009 \\
(0.011) \\
{[0.785]}\end{array}$ & $\begin{array}{l}-0.011 \\
(0.011) \\
{[0.954]}\end{array}$ & $\begin{array}{l}-0.013 \\
(0.011) \\
{[1.198]}\end{array}$ & $\begin{array}{l}-0.014 \\
(0.011) \\
{[1.233]}\end{array}$ & $\begin{array}{l}-0.015 \\
(0.011) \\
{[1.414]}\end{array}$ \\
\hline Log of initial SEC (\%) & $\begin{array}{c}0.839 * * \\
(0.220) \\
{[3.823]}\end{array}$ & $\begin{array}{c}0.880^{* *} \\
(0.217) \\
{[4.046]}\end{array}$ & $\begin{array}{c}0.770^{* *} \\
(0.223) \\
{[3.461]}\end{array}$ & $\begin{array}{c}0.872^{* *} \\
(0.216) \\
{[4.035]}\end{array}$ & $\begin{array}{c}0.912^{* *} \\
(0.214) \\
{[4.258]}\end{array}$ & $\begin{array}{c}0.799^{* *} \\
(0.219) \\
{[3.653]}\end{array}$ \\
\hline Government (\% GDP) & $\begin{array}{c}-0.067^{* *} \\
(0.025) \\
{[2.690]}\end{array}$ & $\begin{array}{c}-0.067^{* *} \\
(0.025) \\
{[2.691]}\end{array}$ & $\begin{array}{c}-0.065 * * \\
(0.025) \\
{[2.628]}\end{array}$ & $\begin{array}{c}-0.068 * * \\
(0.024) \\
{[2.806]}\end{array}$ & $\begin{array}{c}-0.069 * * \\
(0.024) \\
{[2.809]}\end{array}$ & $\begin{array}{c}-0.067 * * \\
(0.024) \\
{[2.742]}\end{array}$ \\
\hline Log of initial GDP & $\begin{array}{c}-0.330^{* *} \\
(0.126) \\
{[2.626]}\end{array}$ & $\begin{array}{c}-0.327^{* *} \\
(0.125) \\
{[2.618]}\end{array}$ & $\begin{array}{c}-0.307^{*} \\
(0.123) \\
{[2.493]}\end{array}$ & $\begin{array}{c}-0.321^{* *} \\
(0.124) \\
{[2.596]}\end{array}$ & $\begin{array}{c}-0.316^{*} \\
(0.123) \\
{[2.567]}\end{array}$ & $\begin{array}{c}-0.304 * \\
(0.121) \\
{[2.517]}\end{array}$ \\
\hline$R$-bar Squared & 0.259 & 0.259 & 0.266 & 0.282 & 0.281 & 0.290 \\
\hline
\end{tabular}

Source: Authors' analysis based on data sources discussed in the text.

Notes: ${ }^{\dagger}, *$ and $* *$ indicate significance at the $10 \%, 5 \%$ and $1 \%$ levels, respectively. Standard errors are in parentheses, while tstatistics are in brackets. Growth rates are five-year averages. Network measures are five-year averages; their initial values in each five-year period are used as instruments for the corresponding five-year averages. All equations also include country fixed effects and time fixed effects that are not shown. Estimation is by two-stage least squares. The sample size in each equation is 464 . 
Table 5: Instrumental variables growth regressions with country-fixed effects, 1965-2004, 83 Countries

\begin{tabular}{|c|c|c|c|c|c|c|}
\hline \multirow[b]{2}{*}{ Variables } & \multicolumn{6}{|c|}{ Dependent Variable: Growth of Per Capita Income (\%) } \\
\hline & (1) & $(2)$ & (3) & $(4)$ & (5) & (6) \\
\hline \multirow[t]{3}{*}{ Export Degree } & $0.058 * *$ & & & $0.052^{* *}$ & & \\
\hline & $(0.016)$ & & & $(0.016)$ & & \\
\hline & [3.685] & & & [3.337] & & \\
\hline \multirow[t]{3}{*}{ Export Closeness } & & $0.100^{* *}$ & & & $0.089 * *$ & \\
\hline & & $(0.023)$ & & & $(0.022)$ & \\
\hline & & {$[4.424]$} & & & [4.016] & \\
\hline \multirow[t]{3}{*}{ Eigenvector Centrality } & & & $0.293 * *$ & & & $0.280^{* *}$ \\
\hline & & & $(0.099)$ & & & $(0.096)$ \\
\hline & & & [2.958] & & & [2.913] \\
\hline \multirow[t]{3}{*}{ Trade (\% of GDP) } & & & & $0.034 * *$ & $0.034^{* *}$ & $0.037 * *$ \\
\hline & & & & $(0.011)$ & $(0.010)$ & $(0.010)$ \\
\hline & & & & [3.269] & {$[3.246]$} & [3.562] \\
\hline \multirow[t]{3}{*}{ M3 (\% GDP) } & -0.009 & -0.013 & -0.007 & -0.014 & -0.018 & -0.013 \\
\hline & $(0.012)$ & $(0.012)$ & $(0.012)$ & $(0.012)$ & $(0.012)$ & $(0.012)$ \\
\hline & {$[0.744]$} & [1.090] & [0.589] & [1.201] & [1.512] & [1.080] \\
\hline \multirow[t]{3}{*}{ Inflation (\%) } & -0.005 & -0.007 & -0.004 & -0.015 & -0.016 & -0.014 \\
\hline & $(0.016)$ & $(0.016)$ & $(0.016)$ & $(0.015)$ & $(0.015)$ & $(0.015)$ \\
\hline & {$[0.336]$} & {$[0.429]$} & {$[0.256]$} & {$[0.956]$} & [1.037] & {$[0.946]$} \\
\hline \multirow[t]{3}{*}{ Log of initial SEC (\%) } & $-1.118^{* *}$ & $-1.124 * *$ & $-1.314^{* *}$ & $-1.052 *$ & $-1.058^{* *}$ & $-1.239 * *$ \\
\hline & $(0.421)$ & $(0.419)$ & $(0.432)$ & $(0.410)$ & $(0.408)$ & $(0.419)$ \\
\hline & {$[2.655]$} & [2.684] & [3.040] & [2.568] & [2.596] & [2.957] \\
\hline \multirow[t]{3}{*}{ Government (\% GDP) } & $-0.081^{\dagger}$ & $-0.096 *$ & -0.064 & $-0.086^{\dagger}$ & $-0.099 *$ & -0.070 \\
\hline & $(0.048)$ & $(0.048)$ & (0.049) & $(0.047)$ & $(0.046)$ & $(0.048)$ \\
\hline & [1.684] & [2.003] & [1.305] & [1.848] & [2.139] & [1.478] \\
\hline \multirow[t]{3}{*}{ Log of initial GDP } & $-3.503^{* *}$ & $-3.326 * *$ & $-2.863^{* *}$ & $-3.346 * *$ & $-3.193 * *$ & $-2.790 * *$ \\
\hline & $(0.634)$ & $(0.608)$ & $(0.598)$ & $(0.620)$ & $(0.594)$ & $(0.581)$ \\
\hline & [5.528] & {$[5.474]$} & [4.789] & [5.398] & [5.373] & [4.802] \\
\hline$R$-bar Squared & 0.403 & 0.409 & 0.399 & 0.434 & 0.439 & 0.434 \\
\hline
\end{tabular}

Source: Authors' analysis based on data sources discussed in the text.

Notes: ${ }^{\dagger}, *$ and $* *$ indicate significance at the $10 \%, 5 \%$ and $1 \%$ levels, respectively. Standard errors are in parentheses, while tstatistics are in brackets. Growth rates are five-year averages. Network measures are five-year averages; their initial values in each five-year period are used as instruments for the corresponding five-year averages. All equations also include time fixed effects that are not shown. Estimation is by two-stage least squares. The sample size in each equation is 464 . 
Figure 1: Export flows between eight countries
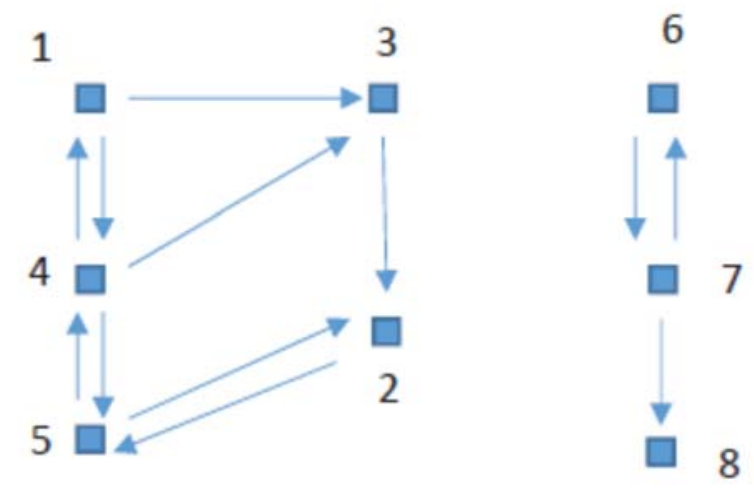

Figure 2: Export flows between eight countries including exports from country 2 to country 8

(a)

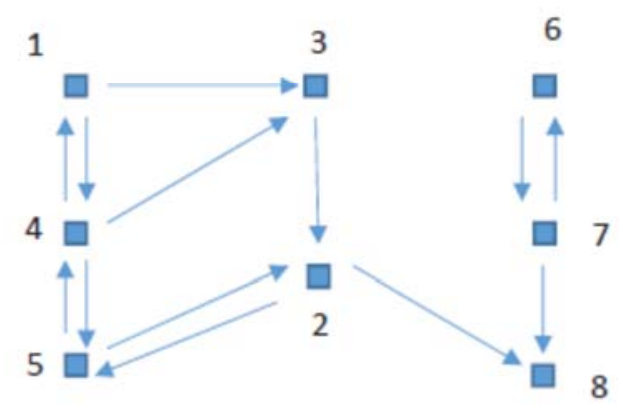

(b)

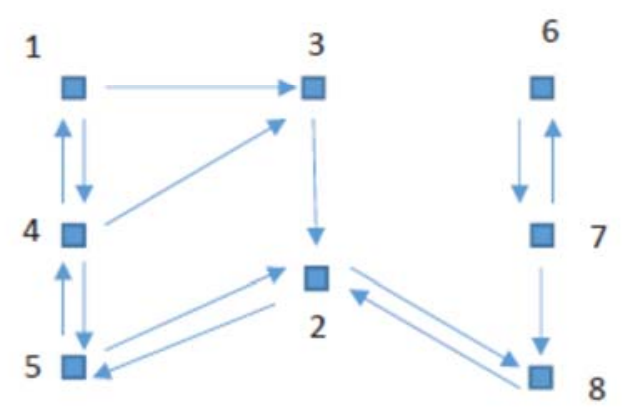


Figure 3: Trade Network Centralities for the United States, 1965-2004
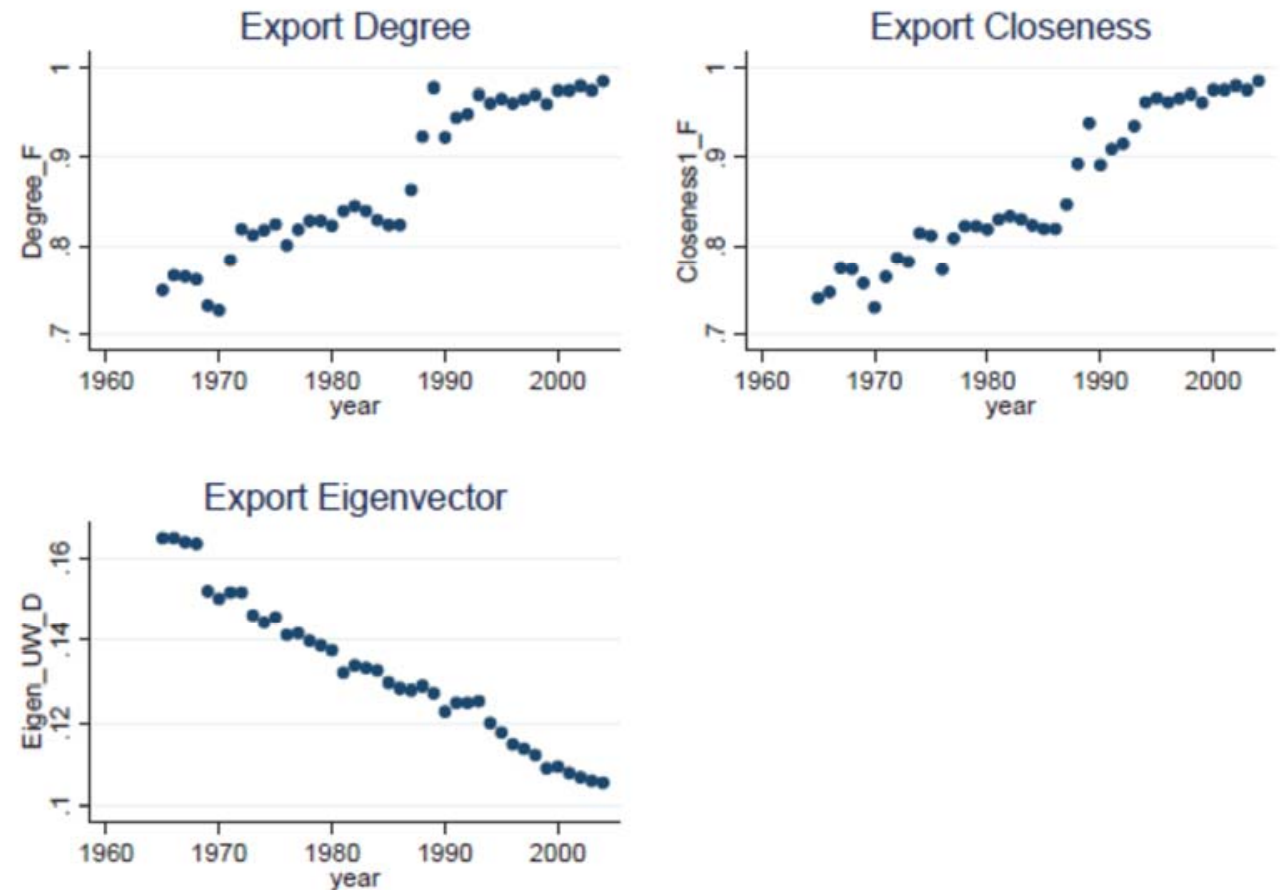

Figure 4: Trade Network Centralities for Brazil, 1965-2004

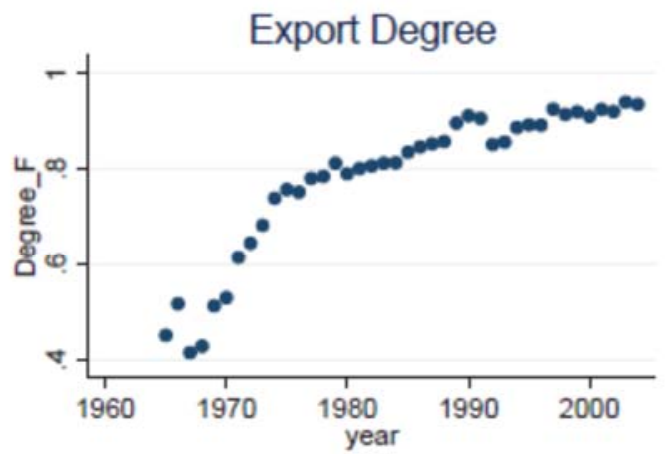

Export Closeness
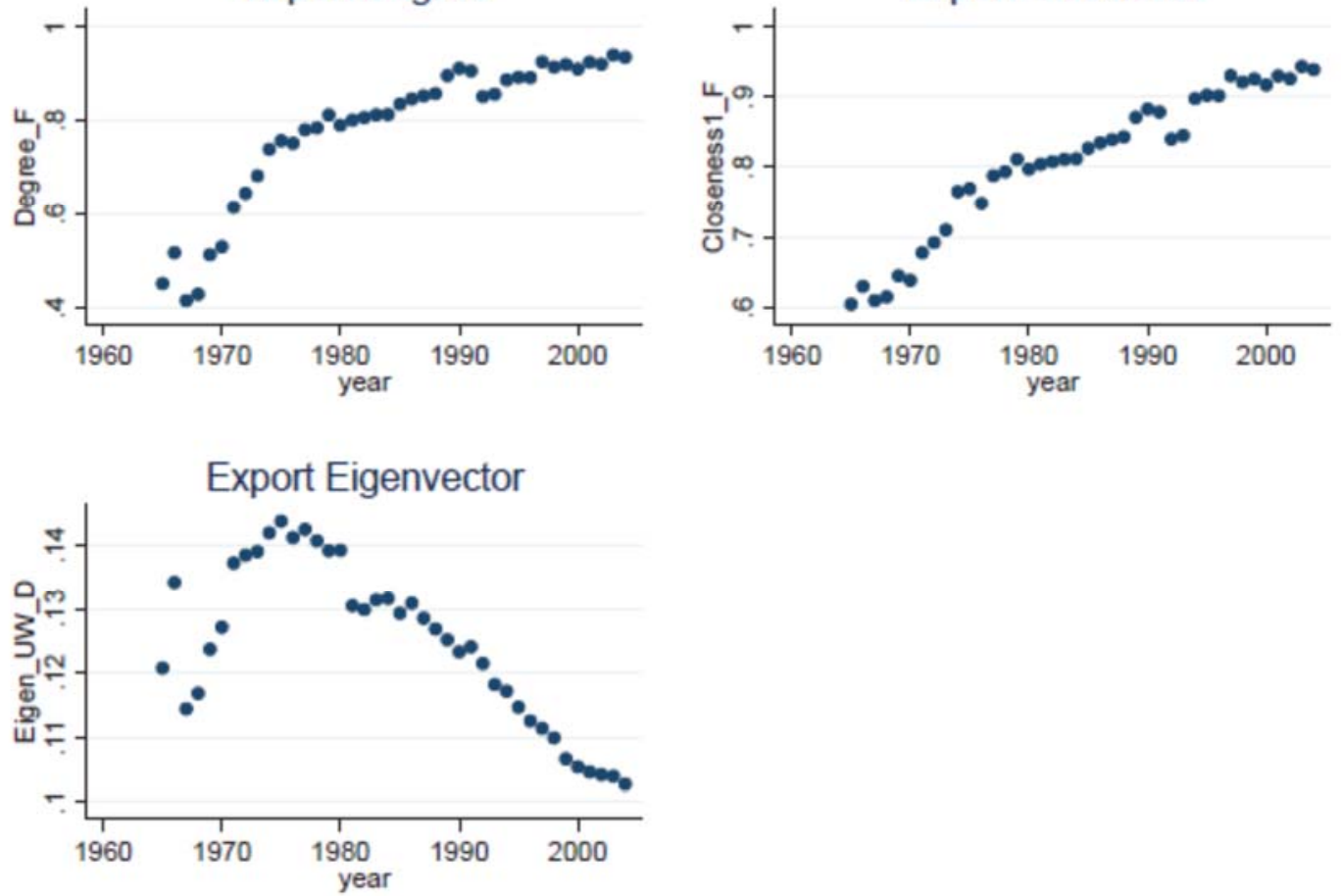
Figure 5: Trade Network Centralities for Israel, 1965-2004
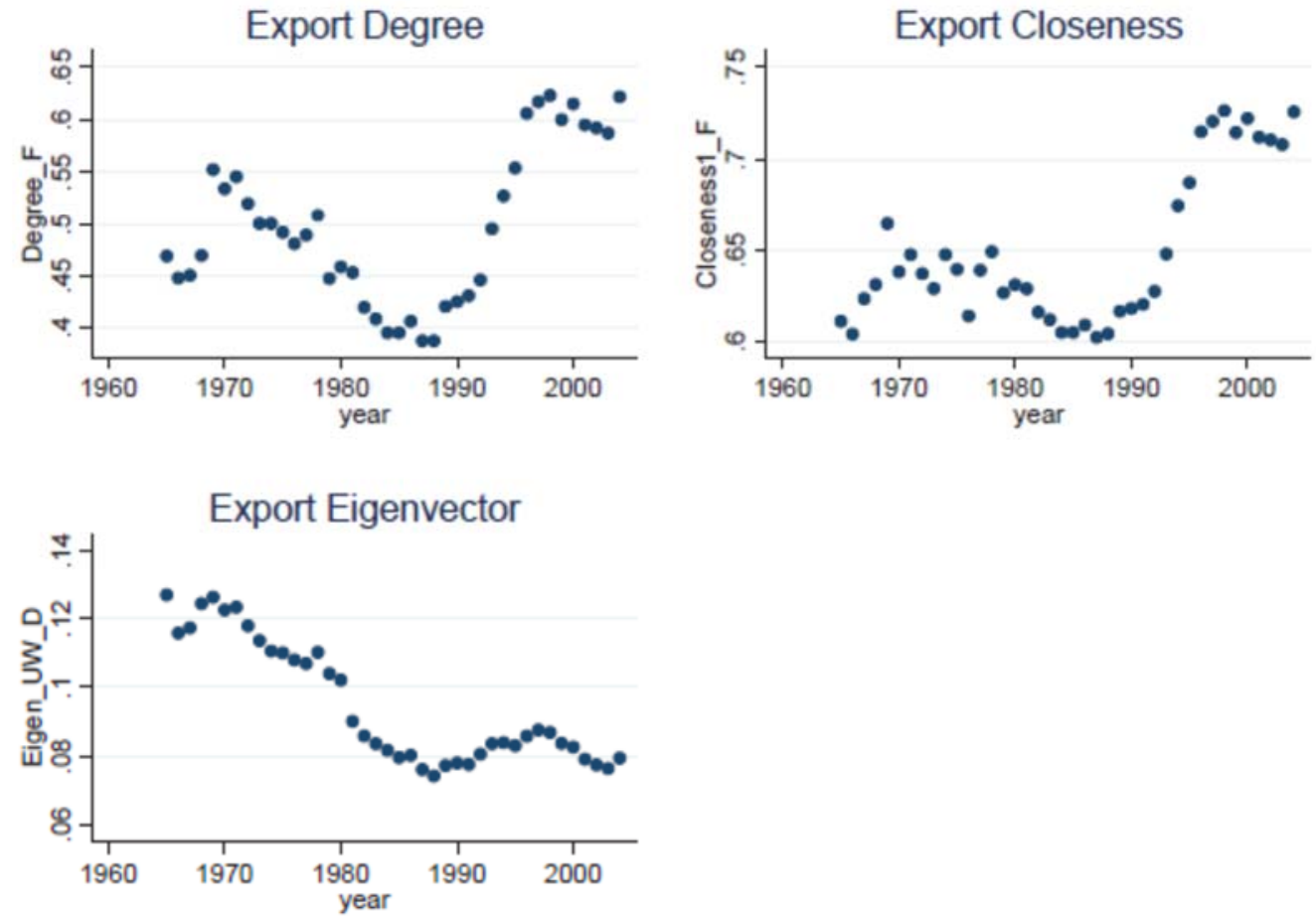

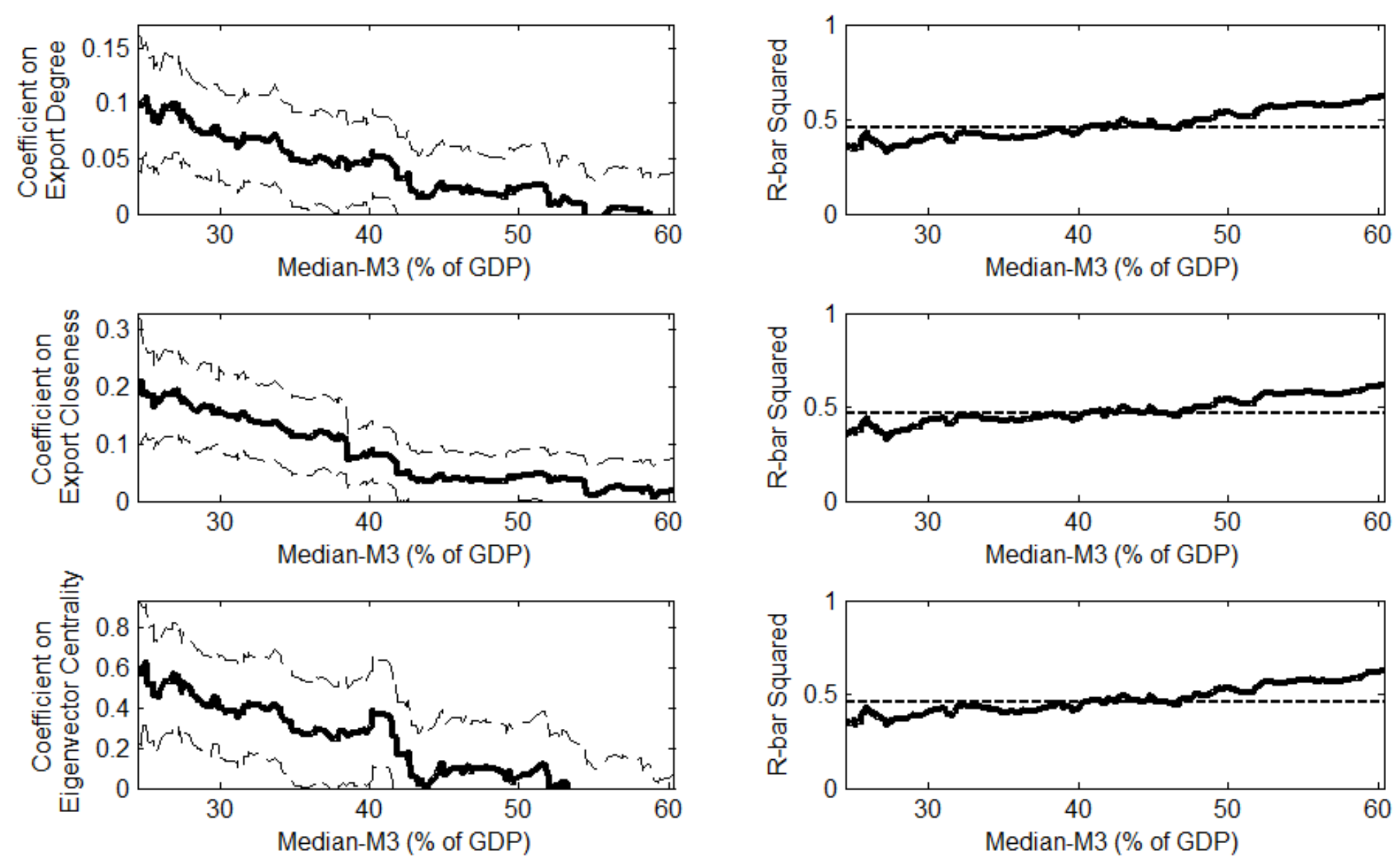

Source: Authors' analysis based on data sources discussed in the text.

Notes:: The dashed lines in the figures of left panel show the 10 percent confidence intervals, while the dashed lines in the figures of right panel show the mean of R-bar squared values. 

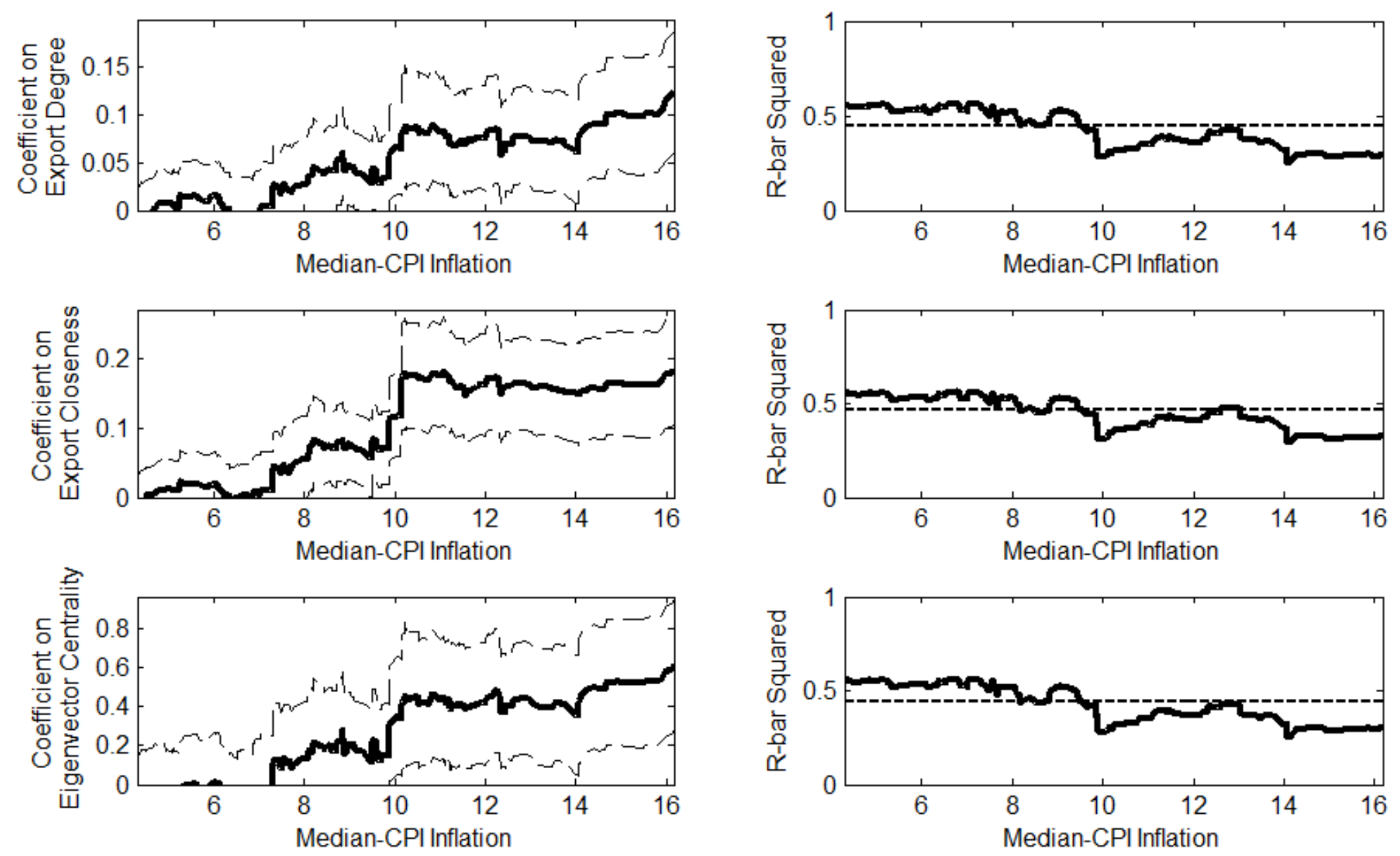

Source: Authors' analysis based on data sources discussed in the text.

Notes:: The dashed lines in the figures of left panel show the 10 percent confidence intervals, while the dashed lines in the figures of right panel show the mean of R-bar squared values. 

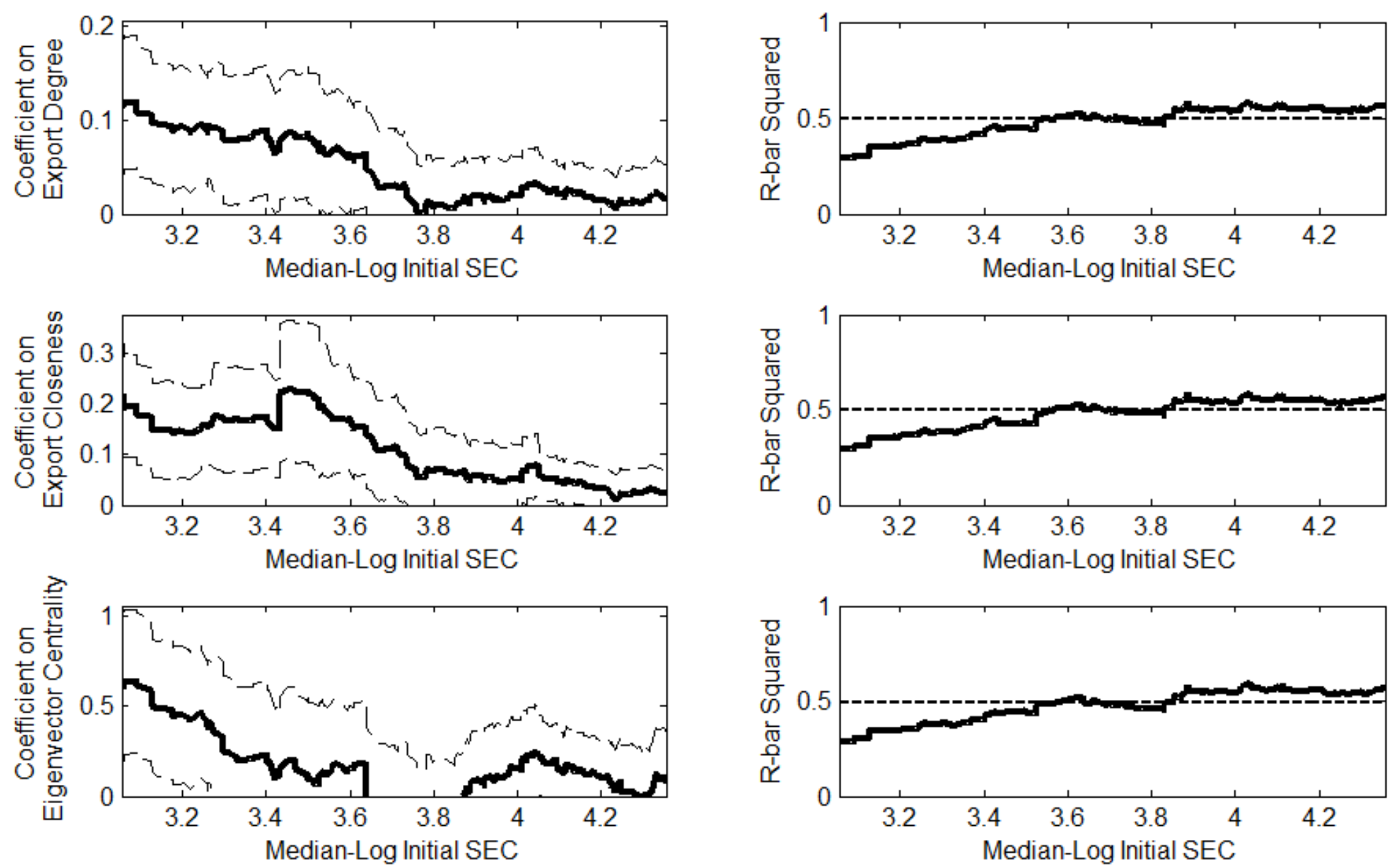

Source: Authors' analysis based on data sources discussed in the text.

Notes:: The dashed lines in the figures of left panel show the 10 percent confidence intervals, while the dashed lines in the figures of right panel show the mean of R-bar squared values. 

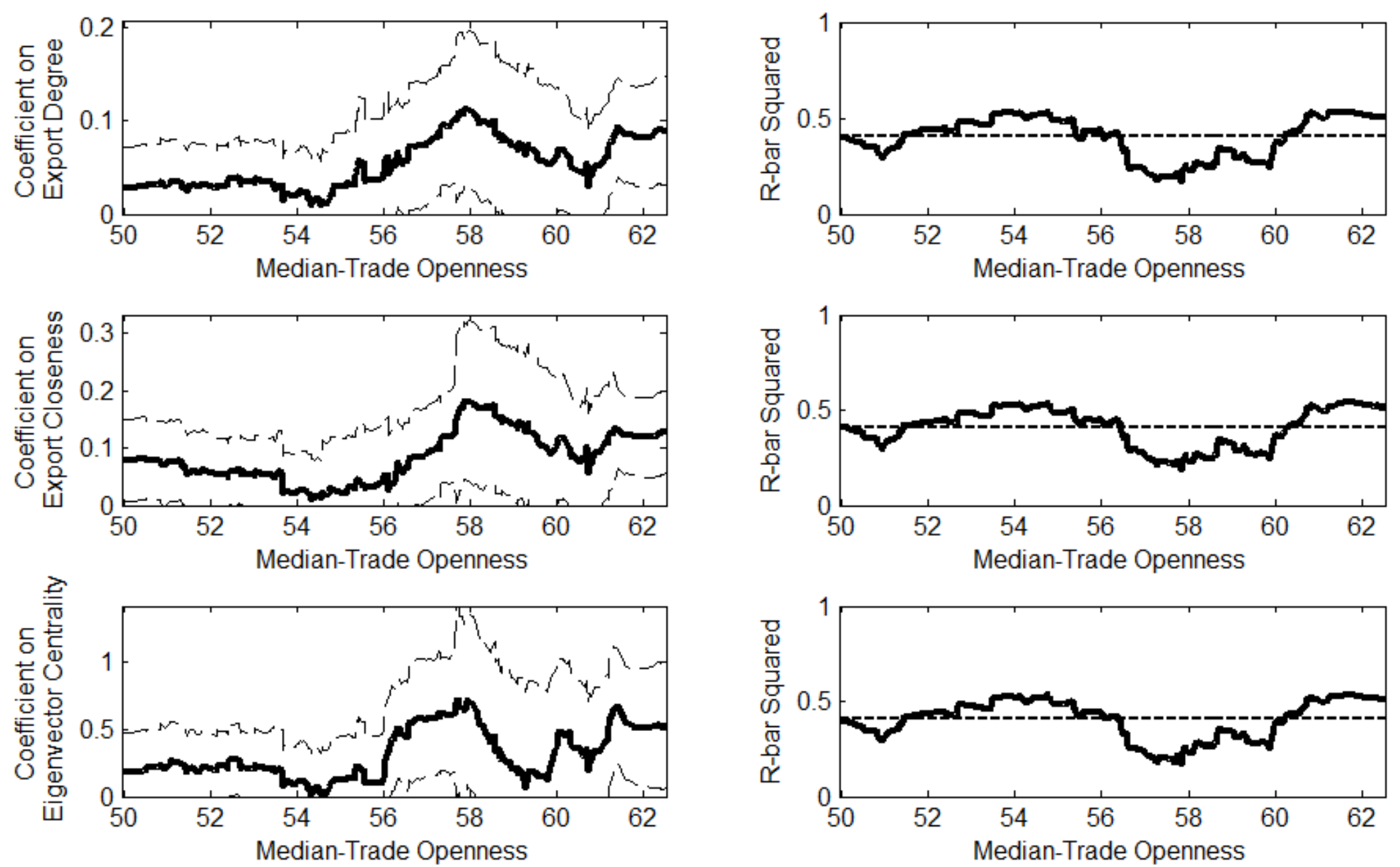

Source: Authors' analysis based on data sources discussed in the text.

Notes:: The dashed lines in the figures of left panel show the 10 percent confidence intervals, while the dashed lines in the figures of right panel show the mean of R-bar squared values. 

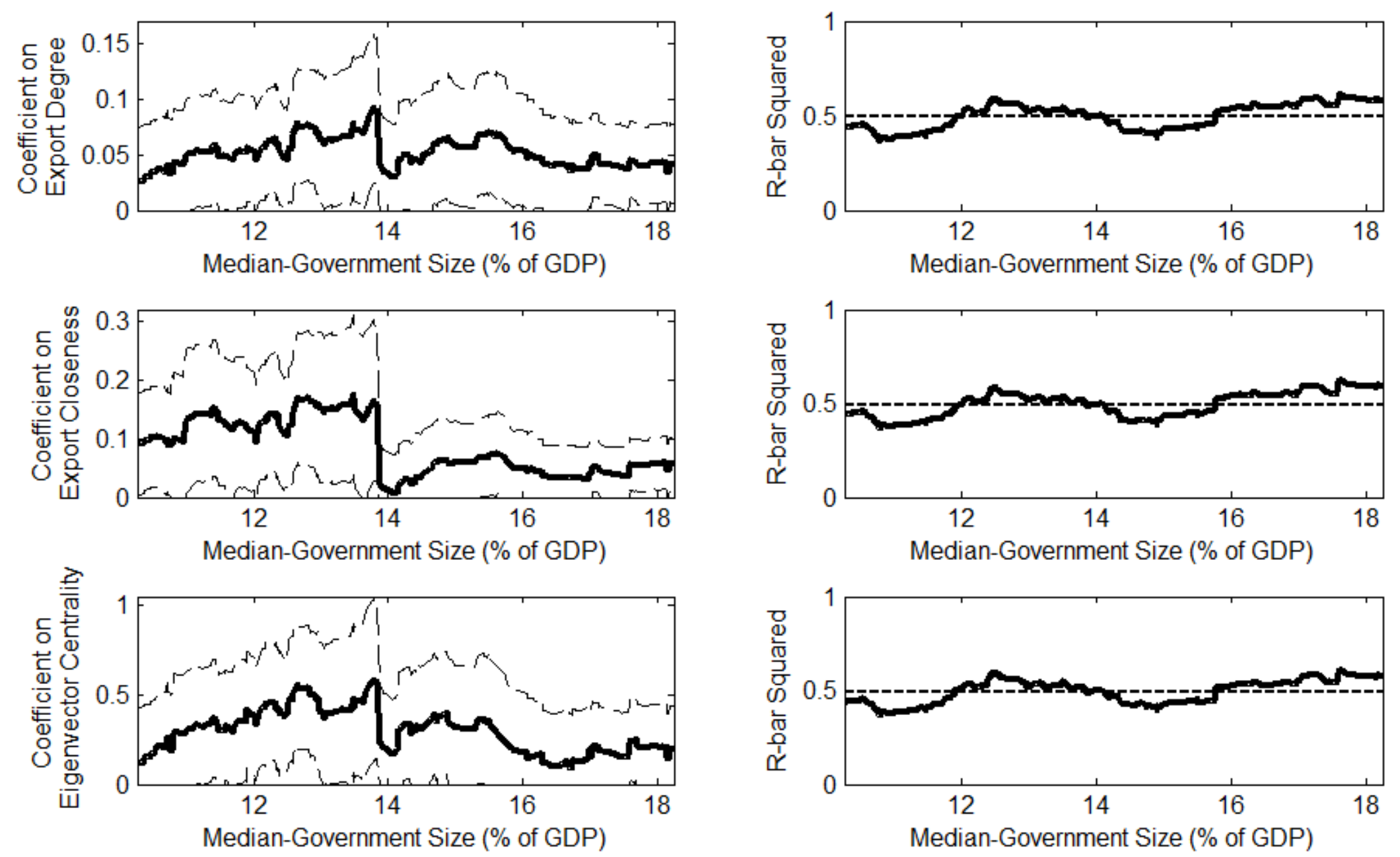

Source: Authors' analysis based on data sources discussed in the text.

Notes:: The dashed lines in the figures of left panel show the 10 percent confidence intervals, while the dashed lines in the figures of right panel show the mean of R-bar squared values. 

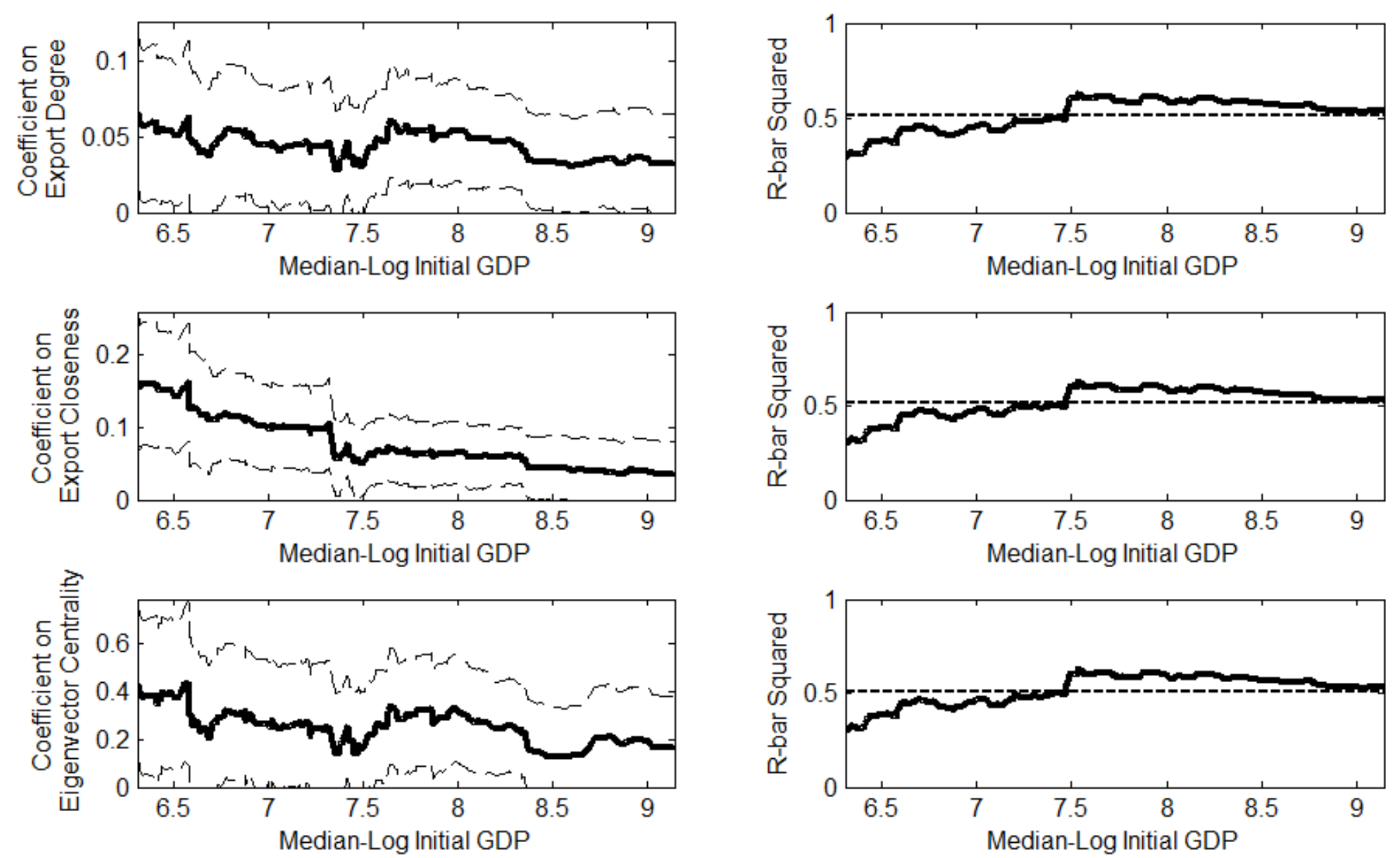

Source: Authors' analysis based on data sources discussed in the text.

Notes:: The dashed lines in the figures of left panel show the 10 percent confidence intervals, while the dashed lines in the figures of right panel show the mean of R-bar squared values. 